\title{
Juan Antonio Frago: una historia dura del español de América*
}

\author{
Alfredo Matus Olivier \\ Universidad de Chile
}

Está en el campo de Borja, el de los Borja, el de los Borgia, en la médula espinal de Aragón. Mira hacia el sagrado y celtíbero Moncayo, ya cantado por Marcial, monte exento que se asoma al valle del Ebro, en la España más carpetovetónica, en el sentido amplio del gentilicio. Las primeras noticias nos hablan de los iberos, de sus restos de sílice y cerámica, de sus monedas. Se llama Magallón, y de él ha salido también otro lingüista excepcional, Fernando Lázaro Carreter, quien fuera director de la Real Academia Española. La última de sus nuevas data de hoy, 7 de noviembre de 2012, de aquí, de este campus universitario, en que uno de sus hijos más señalado recibe el Doctorado Honoris Causa de una de las universidades iberoamericanas más prestigiosas, la Universidad de Chile. Su nombre ya está inscrito en la lista de los principales historiadores de la lengua española. Tiene su residencia en este pueblo aragonés, en la calle Juan Antonio Frago $\mathrm{n}^{\circ} 23$, y se llama Juan Antonio Frago Gracia, por la gracia de Dios.

El relieve intelectual de este investigador magallonero es macizo. En su trayectoria académica y humana hay solidez y fortalezas sin porosidades ni magulladuras. La primera de sus fortalezas radica en su cónyuge, que ahora nos acompaña, $\mathrm{D}^{\mathrm{a}}$ Blanca Amada, bilbilitana de raigambre, de esa Calatayud de la Dolores y de Marcial ("El que prefiere regalar la mitad a

${ }^{*}$ Laudatio para el Doctorado Honoris Causa otorgado por la Universidad de Chile a D. Juan Antonio Frago, Santiago, 7 de noviembre de 2012. 
Lino antes que prestarle todo, prefiere perder la mitad", epigrama LXXV, Mal pagador, en Epigramas de Marco Valerio Marcial, a cargo de Fidel Argudo, Zaragoza, 2003).

Trayectoria compacta, la de este científico del hablar humano en su dimensión histórica, en su hacerse, en su perpetuo constituirse, puesto que las lenguas no están fraguadas en definitiva sino que se están permanentemente haciendo en la actividad pragmática, discursiva y textual, cotidiana. El cambio no es más que la sorprendente creatividad lingüística que, cada vez que lo pensamos, nos deja perplejos. Ignacio Bosque, en la recepción del Doctorado Honoris Causa por la Universidad Nacional de Córdoba (Argentina), en 1911 decía: "[...] no cabe duda de que existe cierta tensión en el simple hecho de que poseamos las palabras, a la vez que ellas nos poseen a nosotros. La creatividad lingüística no queda, desde luego, mermada cuando descubrimos que la lengua es un gigantesco armazón mental, ya que gracias a ese armazón podemos construir cuanto queda al alcance de nuestro pensamiento o de nuestra imaginación".

La reconocida solidez de este historiador del español de América, Juan Antonio Frago, que ha sido catedrático en Sevilla, Málaga y Zaragoza, se sostiene en su condición de viejo investigador, no anciano, que va a las cosas mismas, que mete los brazos en el barro, en la empiria misma. Repetidas veces escuché a mi maestro Eugenio Coseriu sostener: "El que no sabe de las cosas habla de los métodos". Juan Antonio Frago sabe de las cosas y habla de las cosas, habla de lo que sabe. Potente ha sido su reconstrucción de una historia del español americano, enérgicamente fundada en los datos y, por tanto, irrebatible. Su obra está impregnada en la realidad; son muchos, inconmensurables, los datos que maneja, aunque está convencido asimismo -y lo demuestra- de que historiar no consiste en mera acumulación sino en hermenéutica, en interpretación de los datos, arrojo de inteligibilidad y, por tanto, de sentido, esa "sombra mística que sobre [la materialidad de una cosa] vierte el resto del universo", en el decir de Ortega y Gasset. En esto radica la "dureza" de este quehacer investigativo de Juan Antonio Frago, que ha articulado una auténtica "historia dura del español de América". No solo las ciencias naturales y las llamadas "exactas" producen conocimiento "duro".

Basta asomarse al potente y variado - variedad en la unidad- espectro de sus publicaciones. Más de doscientas, entre ensayos y libros científicos, ostenta este estudioso, representante del mejor hispanismo contemporáneo. No puedo, por cierto, remover en todos sus detalles cada uno de los estudios. Me conformo, más bien, con aludir someramente a sus principales campos de interés. Como pocos, en el Dr. Frago se hace rotunda la sentencia orteguiana: Frago es él y su circunstancia, y su circunstancia vital se ha anclado en tres núcleos geográficos: Aragón (Zaragoza, su solar originario y la tierra de 
sus ancestros y descendencia), Andalucía (Sevilla y Málaga, donde enseñó e investigó por más de diez años) y, con Andalucía, y su inconmensurable Archivo de Indias, en el que se contiene gran parte de su conformación, América Española. Lealtad férrea a sus tópoi existenciales. Reconozco algunas matrices en que ha centrado su reflexión, matrices todas que, en su extraordinaria riqueza, conforman una red solidaria, unidad de pensamiento, enmarcada siempre dentro del contexto indoeuropeo y románico.

La lingüística y la filología navarro-aragonesa, en la que ha explorado campos como los de la toponimia, las relaciones navarro-aragonesas y riojanas, la onomástica antroponímica y toponímica medieval, la fonética histórica, la dialectología, la flora y la fauna medievales, la sociolingüística, la crítica documental, las relaciones navarro-aragonesas con el occitano, el sustratismo vasco, las asimilaciones, el yeísmo, la tradición y el folclore, la literatura, el helenismo culto.

La lingüistica hispánica constituye otra de sus perspectivas, con exploraciones de tanta centralidad como el reajuste fonológico, la velarización española, la toponimia de Aragón, el castellano hasta la expansión americana, el léxico y la pronunciación del Siglo de Oro, cultura lingüística del Renacimiento, los arabismos subsaharianos, el dominio leonés, el léxico de la prostitución del siglo XV, el léxico de la arquitectura, el español y las ideas de Gracián, el tratamiento personal en el Quijote, la norma y el arquetipo en La lozana andaluza, por recordar solo algunas.

Por cierto, la vertiente a la que D. Juan Antonio Frago ha entregado su mayor dedicación, a la que yo llamaría con propiedad lingüística atlántica, puesto que se refiere a las conexiones genéticas entre el andaluz, el canario y el español americano dentro de una concepción arquitectural de la lengua española, al mismo tiempo diacrónica, diatópica y diastrática, e incluso diafásica, concepción que, en verdad, inspira todos sus trabajos filológico -lingüísticos. En esta línea podemos señalar monografías sobre orígenes y expansión del seseo, la -s en las hablas andaluzas, historia del léxico y de la fonética andaluzas, el andaluz y el extremeño, las hablas canarias, el andaluz y el español de América, la documentación indiana, castellano-leoneses en las Indias, japonesismos, la lengua de los cronistas, criollización lingüística, escritores franciscanos en América en el siglo XVII, dominicos en el Nuevo Mundo, estudios sobre la historia lingüística de Venezuela, Colombia, Chile, el área antillana, la Nueva España, la zona rioplatense, el afroamericanismo léxico, los marinerismos de tierra adentro, el léxico en la prensa bolivariana, estudios sobre la Independencia, la conciencia lingüística del criollo.

A todo lo cual se agregan, con fuerte personalidad, los trabajos de corte teórico-metodológico, como criterios de afijación, estrategias para la investigación del español de América, la documentación del Archivo de 
Indias, métodos en la enseñanza de la toponimia, dialectología e historia de las lenguas, las jergas, cuestiones ortográficas en examen histórico, apuntes documentales y metodológicos sobre la criollización, fundamentos documentales y metodológicos del afroamericanismo léxico. En lo que concierne a la historia del español de América habría que dividir la obra de Frago en estudios coloniales muy abundantes y macizos que, para no pecar de prolijo, no menciono, y estudios del español en la Independencia, los más recientes, entre los cuales no puedo dejar de aludir a algunos: "Tradición e innovación en el español americano de la Independencia" (2007), "Conciencia lingüística del criollo en la Independencia" (2008), "Textos y geografía del marinerismo de tierra adentro. El Río de la Plata" (2008), "Marinerismos de tierra adentro. Del Río de la Plata a México" (2008), "Conciencia lingüística del criollo en la Independencia: hablar castellanocolombiano" (2008), "El Río de la Plata y Chile en la Independencia" (2010, texto de la conferencia plenaria para el V Congreso Internacional de la Lengua Española), "Notas sobre el español rioplatense y chileno en los años de la Independencia" (2010), "Sobre el español de Chile: del período colonial al independiente" (2010), "Cruces normativos y dialectales en la Proclama del chusco de Arequipa (c. 1810)" (2012), "Razones de las reformas ortográficas en la América independiente y causas del fracaso" (2012), materia esta, del español en el período independiente, completamente desatendida por los estudiosos, en que el catedrático de Zaragoza puede ser considerado un pionero.

Varios de sus trabajos hacen transparente, en el título, la base documental en que se apoyan, como, por ejemplo, documentación jurídica aragonesa, carta notarial del año 1243, fuentes documentales aragonesas, teatro y lírica de los siglos XVI a XVIII, textos periodísticos andaluces, documentos capitulares de Morón, documento aragonés de 1409, documentación indiana del siglo XVI, texto aragonés dieciochesco, textos literarios del Siglo de Oro, manuscritos mexicanos, cronistas de Indias, cartas de emigrados andaluces, documentos de la Nueva España, códice cidiano, documentación canaria, texto anónimo rioplatense, prensa boliviana. La variedad tipológica de fuentes es asimismo sorprendente en las obras del humanista zaragozano; por aducir un solo ejemplo, en su libro sobre El español de América en la Independencia (2010), se escudriña un corpus compuesto por relaciones tipográficas, mapas, libros de viaje, crónicas, cartografía virreinal, plantas urbanísticas, exvotos, textos folclóricos y periodísticos, entre otras. Importantes obras ha dedicado este sabio aragonés a la comprensión y la génesis de nuestra lengua materna, de tan imprevisibles dimensiones y destinos en su actual extensión universal, como cuarta lengua del mundo desde un punto de vista demolingüístico, y como segunda y prioritaria en los países de idiomas diferentes al español. 
Baste recordar algunos trabajos considerados canónicos entre los estudiosos de la historia lingüística hispánica. Y esta no es más que una punta de iceberg del monumental corpus teórico con duro respaldo empírico de sus trabajos mayores, representados por sus libros, tratados y manuales, como Toponimia del Campo de Borja. Estudio lexicológico (1980), donde me encuentro con la fórmula toponomástica, tan frecuente en Chile, de Lo Valledor, Lo Espejo, Lo Barnechea; Historia de las hablas andaluzas (1993), un clásico de los estudios históricos meridionales; El andaluz y el español de América. Historia de un parentesco lingüistico (1994), el título lo dice todo; Historia del español de América. Textos y contextos (1999), obra fundamental para conocer la índole del español americano en la historia de la lengua española; Textos y normas. Comentarios lingüísticos (2002), de gran valor metodológico para el estudio documental de la lengua española en general; El español de América en la Independencia (2010), ya mencionado, escrito especialmente para la Academia Chilena de la Lengua, con motivo del $V$ Congreso Internacional de la Lengua Española (marzo de 2010) y que hubo de suspenderse por el sismo del 27 de febrero, primer estudio que trata comprensivamente el período independiente en la historia lingüística americana.

Prolijo sería continuar desmenuzando la trayectoria científica tan destacada como fecunda de D. Juan Antonio Frago, doctor por la Universidad de Zaragoza (1974), catedrático emérito de Historia de la Lengua Española por esa misma casa de estudios (2010), Premio del XIV Concurso de Tesis de Licenciatura sobre Temas Aragoneses (1973), Premio Internacional de Investigación "Andalucía y América" (1990), Académico Correspondiente por Aragón de la Real Academia Española (1995), Académico correspondiente por España de la Academia Chilena de la Lengua (1995), Miembro Numerario del Instituto de Estudios Canarios (1999), entre tantos otros merecimientos. Ni me asomo a la enorme labor docente de este catedrático, a las tesis doctorales dirigidas, a sus numerosísimas conferencias en diversas universidades del mundo, a la organización y participación en congresos internacionales y reuniones científicas.

Según lo estipulado en el Reglamento de Distintivos, Distinciones y Calidades Académicas de la Universidad de Chile, en su artículo $10^{\circ}$ : "La distinción Doctorado Honoris Causa podrá concederse a personas de nacionalidad chilena o extranjera, que no sean miembros de la Universidad de Chile y que, en virtud de sus méritos o sobresalientes acciones en beneficio del estudio de la nación chilena o de la humanidad, se han destacado a nivel nacional o internacional". El Prof. Dr. Juan Antonio Frago Gracia reúne, con creces, condiciones y calidades humanas y académicas, mucho más que suficientes para hacerse acreedor de tal distinción. Por una parte, es un 
destacado especialista en su área, el de la historia del español y, de un modo particular, del español americano, de reconocido prestigio internacional, que se ha consagrado al incremento del mejor conocimiento de la génesis y evolución de la lengua española en América, saber fundamental en sí mismo y para el desarrollo de otras áreas del americanismo cultural y social. Por otra parte, candidatos con el exigente y rigoroso nivel que, naturalmente, esta Casa de Bello de la mayor excelencia nacional e internacional, requiere, sin duda hay muchos, en las diversas disciplinas científicas, artísticas y humanísticas. Y uno se pregunta por qué a este y no a este otro, puesto que la Universidad no realiza actos antojadizos: no se trata de distinguir por distinguir, eso está claro. El talante del profesor Frago señala un rasgo distintivo de alto valor para este discernimiento: su honda vinculación con este solar originario de don Andrés Bello y con la universitas chilensis por antonomasia. El Dr. Frago Gracia ha realizado cuatro visitas a nuestra institución, como profesor visitante, al Magíster en Lingüística con Mención en Lengua Española, en 1999, 2008, 2010 y 2011, además de la actual, la quinta. En todas ellas se ha destacado como un gran impulsor de la investigación sobre la historia del español americano, causando gran impacto entre los estudiantes y profesores. Por otro lado, ha sido un constante colaborador del Boletín de Filología, fundado en 1934 por Rodolfo Oroz, la revista latinoamericana de lingüística y filología más antigua en el ámbito de la hispanística. En sus páginas ha publicado una docena de ensayos científicos, algunos ya mencionados, en los números correspondientes a los años 1997, 1998-1999, 2000-2001, 2002-2003, 2004-2005, 2007, 2008 (1 y 2), 2010 (1), 2011 (1) y 2012 (2), la mayoría de los cuales constituye consulta obligada para los especialistas en lingüística y filología americanas. En 2000, en reconocimiento a su calidad académica y compromiso con el Boletín, fue nombrado Miembro de su Comité Editorial y, en 2006, Miembro del Comité Científico Asesor. En esta condición, en 2010 propuso la publicación de un número monográfico sobre "La lengua española en la época de la Independencia de las repúblicas americanas (siglo XIX)", el que se realizó con gran éxito de convocatoria. Por todas estas razones, Juan Antonio Frago es reconocido como un ferviente promotor del Boletín de Filología, al que con su personalidad ha contribuido a incrementar su sólido prestigio, y un declarado admirador de la obra del fundador de nuestra corporación, don Andrés Bello.

Juan Antonio Frago es un teórico convencido de que "conocer es distinguir", como sostenía Benedetto Croce. Dentro de este genuino proyecto cognitivo, ha quebrado lanzas por destruir mitos sobre la realidad idiomática americana, metáforas que han conducido a que de lo más que se disponga, en esta compleja materia, sea de generalizaciones que se siguen admitiendo sin el ceñido examen de la razón. ¿Koiné antillana? ¿Base lingüística del español 
de América? ¿Hidalguización? ¿Revolución fonológica? Todo lo somete a crítica metódica, estricta. Andalucismo, sí, pero...Tierras altas y tierras bajas, bien, no obstante...; explicación por contactos, magnífico, aunque... Como he escrito en otro lugar, esta severa obra de creación científica se erige como un auténtico seminario permanente, semillero de indagaciones para los investigadores del futuro. Absolutamente indispensable para los científicos del lenguaje, investigadores, estudiosos y estudiantes, con ella dispondrán de un cúmulo de interrogaciones y noticias fidedignas, punto de partida para cualquier consideración genética de nuestra realidad lingüística. La mayor parte de sus planteamientos, que exhiben una gran finura analítica, constituyen otras tantas sendas abiertas y una amplia y asertiva invitación a recorrerlas según las orientaciones y métodos que él mismo ha demostrado ser competentes en la perspectiva de la reconstrucción diacrónica. Toda su obra constituye una propuesta hermenéutica y de reconstrucción del pasado. Puertas abiertas de par en par; en esto consiste un estudio verdaderamente científico, en esto se fragua el radical imperativo: aquí disponemos de un puñado de sugerentes preguntas e interpretaciones históricas, nunca antes planteadas, o nunca antes articuladas de este modo, un porción de hipótesis plausibles, a modo de inquisiciones, que tenemos la responsabilidad ética de asumir para hacer progresar el conocimiento de nuestra entrañable realidad lingüística, que, en definitiva, constituye el conocimiento de nosotros mismos. Quehacer mayor de interpretación es este, de cultura y de vida. Como pensaba Ortega y Gasset: "Toda labor de cultura es una interpretación - esclarecimiento, explicación o exégesis- de la vida. La vida es el texto eterno, la retama ardiendo al borde del camino donde Dios da sus voces". 